\title{
Waterborne Polyurethane from Polycaprolactone and Tetramethylxylene Diisocyanate: Synthesis by Varying NCO/OH Ratio and Its Characterization as Wood Coatings
}

\author{
Bosco Joseph Vincent, Balasubramaniyan Natarajan* \\ SRM University, Kattankulathur, Tamilnadu, India \\ Email: *natrajan.b@ktr.srmuniv.ac.in
}

Received December 8, 2013; revised December 30, 2013; accepted January 7, 2014

Copyright (C 2014 Bosco Joseph Vincent, Balasubramaniyan Natarajan. This is an open access article distributed under the Creative Commons Attribution License, which permits unrestricted use, distribution, and reproduction in any medium, provided the original work is properly cited. In accordance of the Creative Commons Attribution License all Copyrights (C) 2014 are reserved for SCIRP and the owner of the intellectual property Bosco Joseph Vincent, Balasubramaniyan Natarajan. All Copyright (C) 2014 are guarded by law and by SCIRP as a guardian.

\begin{abstract}
Environmentally friendly, polyacrylic-based polyurethane dispersion (PUD) was synthesised using various molar ratios of polycaprolactone, dimethylolpropionic acid and tetramethyl xylene diisocyanate. Synthesis was carried out in flowing nitrogen atmosphere. The PUD's preparations are free of NMP (n-methyl pyrrolidone), a toxic processing solvent generally used during the preparation of PUD's. The performance of the synthesised polyurethane dispersions with varying $\mathrm{NCO} / \mathrm{OH}$ molar ratio was tested on wood surface. The physical, chemical, thermal and mechanical properties such as viscosity, particle size, chemical resistance, thermal stability and taber abrasion of applied polyurethane dispersion were carried out as a function of $\mathrm{NCO} / \mathrm{OH}$ molar ratio. The PUD's preparation with $\mathrm{NCO} / \mathrm{OH}$ ratio of 1.4 or 1.6 showed better performance as a wood finish and the results are described in the present study.
\end{abstract}

\section{KEYWORDS}

\section{Waterborne; Polyurethane Dispersion; Wood Coatings; NCO/OH Ratio}

\section{Introduction}

The coating of wooden surfaces serves mainly for surface protection and thus increases its lifetime and utility. The most universally used finishes are the transparent coating treatments applied to the surfaces. A large variety of coatings like Varnish, lacquers, conventional solventbased products like polyurethanes, UV-curing, water-based products come under the category of evaporative, reactive and coalescing wood finishes. These finishes are applied by different application techniques such as rolling, spraying, curtain coating, brushing, dipping and manual application on wood surface.

Solvent-based Polyurethane (PU) is a reactive wood coating that was developed in 1947 [1]. PU is flexible polymers prepared by a simple poly addition reaction of polyol with isocyanate. This urethane linkage gives better properties like hardness, weather resistance, chemical

\footnotetext{
${ }^{*}$ Corresponding author.
}

resistance and gloss. Hence it is used in a variety of applications: like industrial parts, building materials, sports goods, medical equipments and adhesives. In addition, polyurethane coatings can be applied over a variety of substrates like metal, plastic, glass and wood [2]. Though conventional solvent-based polyurethanes possess excellent properties required by the coating industry, they are not accepted in many countries owing to its toxicity. Hence it is essential to have environmentally friendly synthesis of polyurethanes without compromising the properties required by the coating industry. Aqueous-based polyurethane is one of such alternate polyurethane systems. These aqueous-based polyurethanes are basically low in volatile organic compound, thus low in toxicity, which leads to less environmental hazard. Preparation of waterborne polyurethane is more challenging than the solvent borne system [3,4]. In addition to good chemical resistance and high flexibility, the better film forming ability at room temperature makes polyurethane dispersion 
(PUD) find a wide variety of applications [5,6] such as foams and thermoplastic elastomers. An aqueous PUD is a binary colloidal system in which PU particles are dispersed in a continuous aqueous medium. In order to disperse in water, ionic group needs to be incorporated in the polyurethane structure. PUD consists of both soft and hard segments [7]. The hard segment consists of isocyanate and chain extenders whereas the soft segment consists of polyol. The soft segment influences the elastic properties of the PUD, whereas hardness and mechanical strength [8-10] are influenced by the hard segment.

In the present study, PUD was synthesized with polycaprolactone, dimethylol propionic acid (Bis-MPA) and tetramethyl xylene diisocyanate (TMXDI). PUD was prepared with the same diisocyanate, polycarbonate, catalyst, emulsifying agent, and chain extender; however the $\mathrm{NCO} / \mathrm{OH}$ molar ratio was varied. Ratios of $\mathrm{NH}_{2} / \mathrm{NCO}$ and $\mathrm{COOH} / \mathrm{OH}$ were kept constant. All the synthesis was carried out without processing solvent like N-methyl-2pyrrolidine (NMP), which was also used as coalescent for PUD. NMP performs very well in both these respects due to its excellent solvating power and water miscibility. However, health hazard information on NMP has led us not to use during the environmentally friendly synthesis. PUD synthesis was carried out in flowing nitrogen atmosphere. These aqueous polyurethane dispersions and their dried polymer films were characterized and confirmed for the formation of urethane linkage. The influence of different $\mathrm{NCO} / \mathrm{OH}$ molar ratios on the properties of PUD on wood surface was studied and described below.

\section{Experimental}

\subsection{Materials}

Polycaprolactone (Capa 2101A) and dimethylolopropionic acid (Bis-MPA) from Perstrop AB, tetramethyl xylene diisocyanate (TMXDI) from Cytec, dibutyltin dilaurate (DBTL), triethylamine (TEA) and ethlenediamine (EDA) from Aldrich were obtained to carry out the aqueous based polyurethane dispersion. All materials were used as received along with de-ionized water and no organic solvents were used during the synthesis.

\subsection{Preparation of Waterborne Polyurethane (PUD)}

PUD was synthesized in two main steps. Preparation of NCO-terminated pre-polymer followed by neutralization and chain extension of NCO-terminated pre-polymer [11]. PUD was synthesized with varying NCO/OH molar ratio ranging from 1.2 to 2 as indicated in the Table 1 . $\mathrm{NH}_{2} / \mathrm{NCO}$, TEA/NCO and $\mathrm{COOH} / \mathrm{OH}$ were maintained the same during the preparation of PUD as shown in Table 1.
Table 1. Details on synthesis of PUD's.

\begin{tabular}{cccccc}
\hline & PUD 1 & PUD 2 & PUD 3 & PUD 4 & PUD 5 \\
\hline $\mathrm{NCO} / \mathrm{OH}$ & 1.2 & 1.4 & 1.6 & 1.8 & 2 \\
$\mathrm{NH}_{2} / \mathrm{NCO}$ & 0.81 & 0.81 & 0.81 & 0.81 & 0.81 \\
$\mathrm{TEA} / \mathrm{COOH}$ & 0.85 & 0.85 & 0.85 & 0.85 & 0.85 \\
$\mathrm{COOH} / \mathrm{OH}$ & 0.97 & 0.97 & 0.98 & 0.97 & 0.97 \\
\%NCO in & 1.94 & 3.66 & 5.43 & 6.68 & 7.94 \\
pre-polymer & & & & & \\
Solids content & 40.21 & 40.19 & 40.2 & 40.21 & 40.2 \\
\hline
\end{tabular}

\subsection{Preparation of NCO-Terminated Pre-Polymer}

PUD's were synthesised in a $250 \mathrm{ml}$ round bottom glass reactor with the fitted accessories like mechanical stirrer, a thermometer, a reflux condenser, a gas inlet/outlet and temperature monitoring probe. The reaction was carried out in a constant temperature oil bath and in flowing nitrogen atmosphere. Calculated amount of dimethylolpropionic acid, polycaprolactone were fed into the reactor flask together with the dibutyltin dilaurate. The pre-mixture was heated in the reactor to $80^{\circ} \mathrm{C}$ maintaining the stirrer at $110-130 \mathrm{rpm}$. The temperature of the reactor was reduced to $60^{\circ} \mathrm{C}$ as soon as the pre-mixture was in the molten state. To this molten mixture, TMXDI was added slowly. After the complete addition of TMXDI, the reactor temperature was raised once again to $80^{\circ} \mathrm{C}$. The reaction was allowed to continue until the amount of residual NOC groups reached the theoretical value. The theoretical value of residual NOC group was determined by the standard di-n-butylamine back-titration method [12]. The pre-polymer was cooled and maintained at $35^{\circ} \mathrm{C}$.

\subsection{Neutralisation and Chain Extension of NCO-Terminated Pre-Polymer}

NCO-terminated pre-polymer was neutralised with triethylamine, followed by addition of de-ionized water. In order to get uniform particle size of the emulsion, the addition was carried out with a higher speed of $700-800$ $\mathrm{rpm}$. Completion of neutralisation was confirmed by $\mathrm{pH}$ meter. Once the neutralisation was completed ethylenediamine was added and allowed it cool to room temperature.

\subsection{Characterization}

\subsubsection{Fourier Transform Infrared (FTIR) Spectroscopy}

The IR sepectra of starting monomers and polyurethane dispersion were obtained using Shimadzu-FTIR spectrometer, in the range of 450 to $4000 \mathrm{~cm}^{-1}$.

\subsubsection{Particle Size and Viscosity Measurements}

The particles size of PUD's was measured by using DLS 
(Zetasier, melvern Instrument). The samples were diluted with de-ionised water to adjust the solid content and directly placed in the cell. The temperature of the cell was maintained at $25^{\circ} \mathrm{C}$ and the time of the measurement was $300 \mathrm{~s}$.

The viscosity $(\eta)$ measurements of the dispersions were performed using a Brookfield viscometer. Experiment was carried out at $25^{\circ} \mathrm{C}$ and at a shear rate of 100 $\mathrm{s}^{-1}$.

\subsubsection{DSC Analysis}

Glass transition temperature $\left(\mathrm{T}_{\mathrm{g}}\right)$ of PUD's were measured with NETZSCH-DSC using $15 \mathrm{mg}$ sample. The measurements were carried out at from $-40^{\circ} \mathrm{C}$ to $350^{\circ} \mathrm{C}$ at heating rate of $10 \mathrm{~K} / \mathrm{min}$. under flowing $\mathrm{N}_{2}$ atmosphere using sealed aluminium pans. The temperature of the DSC was calibrated using fixed melting point standards such as In and Sn. The error in the temperature of measurement was $\pm 0.5 \mathrm{~K}$.

\subsubsection{Thermal Stability}

PUD's were diluted with de-ionised water until the solid mass fraction was 20\%. The diluted PUD's were tested for thermal stability (as per ASTM E2550-2010). Testing was carried out at $60^{\circ} \mathrm{C}$ for $24 \mathrm{~h}$ by recording the change in the appearance of the dispersion.

Freeze-thaw stability according to ASTM D6944-2010 [13] was tested on the synthesised PUD's. The PUD's were kept in the refrigerator at $-10^{\circ} \mathrm{C}$ for $18 \mathrm{~h}$, and exposed to room temperature $\left(26^{\circ} \mathrm{C}\right)$ for $6 \mathrm{~h}$. The same procedure was repeated for six times to check for reproducibility. The change in the appearance was recorded to recognize the freeze-thaw stability of the PUD's.

\subsubsection{Chemical Resistance}

The newly synthesised samples were coated on glass panels and allowed to dry for 3 days. The open end of the glass panels was sealed with wax to prevent the migration of water under the film. The panels were then dipped into 3\% (w/w) hydrochloric acid solution, 3\% (w/w) $\mathrm{NaOH}$ solution and $3 \%(\mathrm{w} / \mathrm{w}) \mathrm{NaCl}$ solution for $24 \mathrm{~h}$. The change in the appearance was monitored.

The solvent resistance test was carried out as per the double rub test using a piece of white cotton cloth on the coated panels according to ASTM D5402-06 (2011) with the film thickness of $75 \mu \mathrm{m}$. The solvents used were acetone, methyl ethyl ketone and methyl benzene. The result reported was the minimum number of double rubs at which the films were observed to fail or the maximum number of double rubs carried out.

\subsubsection{Mechanical Properties}

The samples were applied onto open pore teak wood panel using "BYK" bar applicator with the film thick- ness of $75 \mu \mathrm{m}$. Coated panels were dried at room temperature in ventilated atmosphere. The wood panels were tested after 7 days ensuring the full maturation of the coated film. Pencil hardness (according to ASTM D336305(2011)), cross cut adhesion as per ASTM D 3359-2009 and abrasion resistance (according to ASTM D4060-10) were tested using taber abraser.

The sample was also applied over mild steel (degreased) panel and tested for flexibility as per ASTM D52293(2008) in a conical mandrel (1/4 in), according to ASTM D4060-10.

\subsubsection{Storage Stability}

All the PUD's were tested for storage stability by preserving the PUD's in air tight high density polyethylene containers. The stored PUD's were tested for the Newtonian flow every month for a maximum period of one year. The change in the flow was monitored.

\section{Results and Discussion}

\subsection{FTIR Spectroscopy}

The synthesised PUD's were labelled as PUD 1 to PUD 5 with varying NCO/OH ratio as shown in Table 1 . IR spectrum of the starting materials is shown in Figure 1. polycaprolactone (polyol) (Figure 1a) showed the following bands: $\mathrm{OH}$-stretching at 3528 and $3460 \mathrm{~cm}^{-1}$. $\mathrm{CH}$-stretching at 2940 and $2866 \mathrm{~cm}^{-1}$. C=O stretching at $1730 \mathrm{~cm}^{-1}[14,15]$. The functional groups present in polycaprolactone was thus confirmed by IR spectroscopy.

Figure 2 shows the IR spectrum of isocyanate with the following bands: $2264 \mathrm{~cm}^{-1}$ and $2252 \mathrm{~cm}^{-1}$ [14] for NCO stretching and $1368 \mathrm{~cm}^{-1}$ and $1424 \mathrm{~cm}^{-1}$ for CN stretching, confirming the functional groups present in isocyanate.

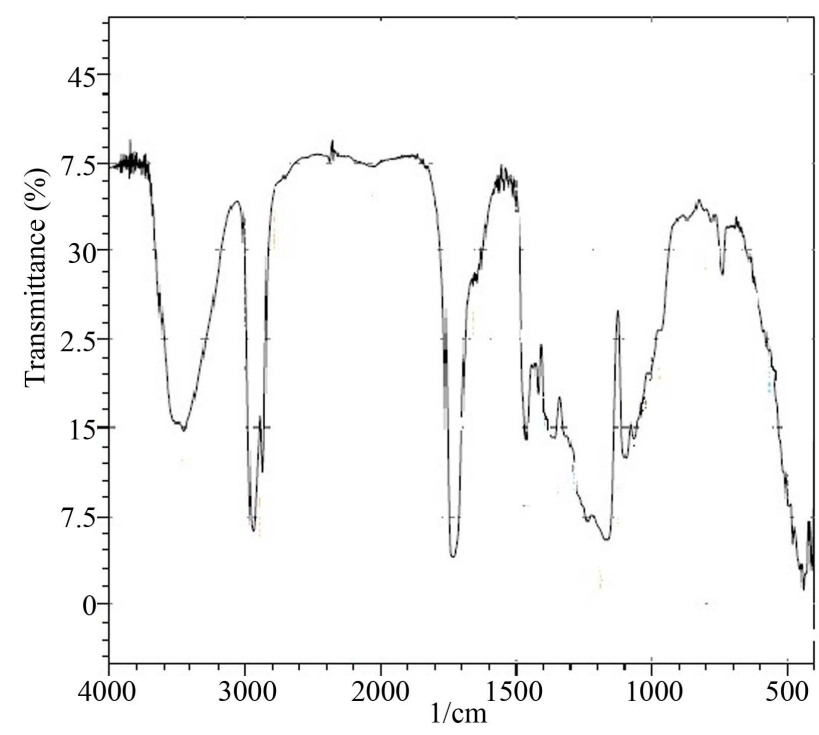

Figure 1. Infrared spectrum of polycaprolactone (polyol). 


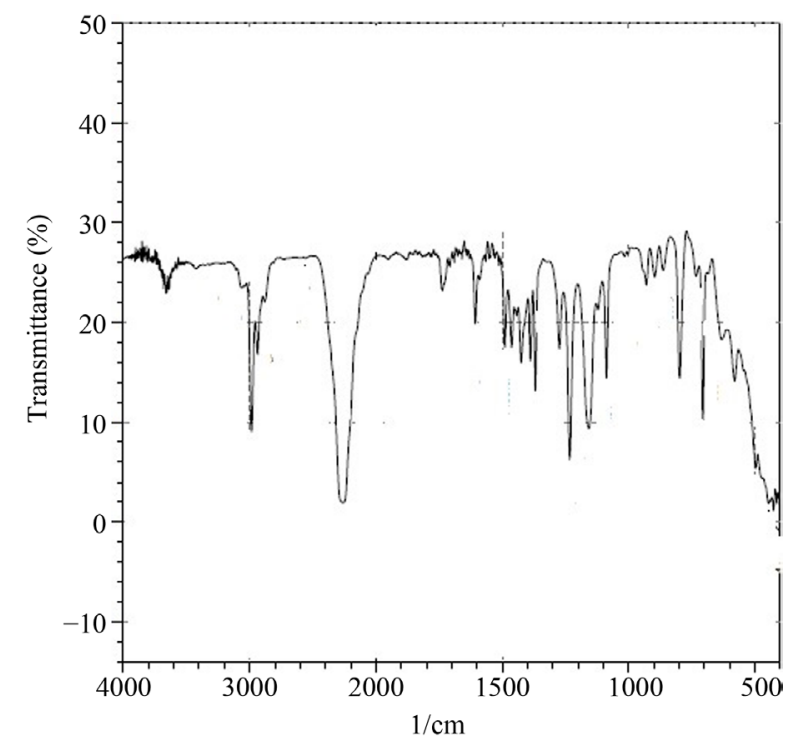

Figure 2. Infrared spectrum of tetramethyl xylene diisocyanate (TMXDI).

Figure 3 shows the representative IR spectrum of PUD 4. The IR spectroscopy analysis of PUD was used to check the end of polymerization reaction. The absence of characteristic NCO band at $2270 \mathrm{~cm}^{-1}$ and appearance of $\mathrm{N}-\mathrm{H}$ stretching bands at $3361-3382 \mathrm{~cm}^{-1}$ confirmed the end of polymerization and formation of polyurethane linkage. The characteristic absorption bands at 2928 $2961 \mathrm{~cm}^{-1}$ indicated the $-\mathrm{CH}_{2}$ asymmetric stretching mode available at the synthesised PUD. The band between 1610 and $1660 \mathrm{~cm}^{-1}$ (m CAN and d NAH), was attributed to amide II stretching modes of polyurethane and polyurea respectively. The band at $1158-1274 \mathrm{~cm}^{-1}$ is due to the asymmetric stretching of $\mathrm{C}-\mathrm{O}-\mathrm{C}$ linkage.

\subsection{Particle Size Analysis and Viscosity Measurements}

Generally, the physical properties of the PUD's depend on molecular structure, availability of the functional groups and the molar ratio of $\mathrm{NCO} / \mathrm{OH}$. Among the various physical properties, particle size and viscosity are of significant parameters which can influence the coating properties of PUD. The PUD's with larger particle size generally undergoes agglomeration, thus possesses shorter shelf life compared to dispersions containing smaller particle size. The higher surface energy of smaller size dispersions facilitates the better film formation. The concentration of hydrophilic group, stirring speed, pre-polymer viscosity and the rate of water addition can certainly influence the particle size of the PUD. Among the various influencing factors, the particle size is greatly influenced by the concentration of carboxylic acid (hydrophilic group) [16,17]. The particle size and viscosity of the synthesised PUD's were presented in Table 2. The

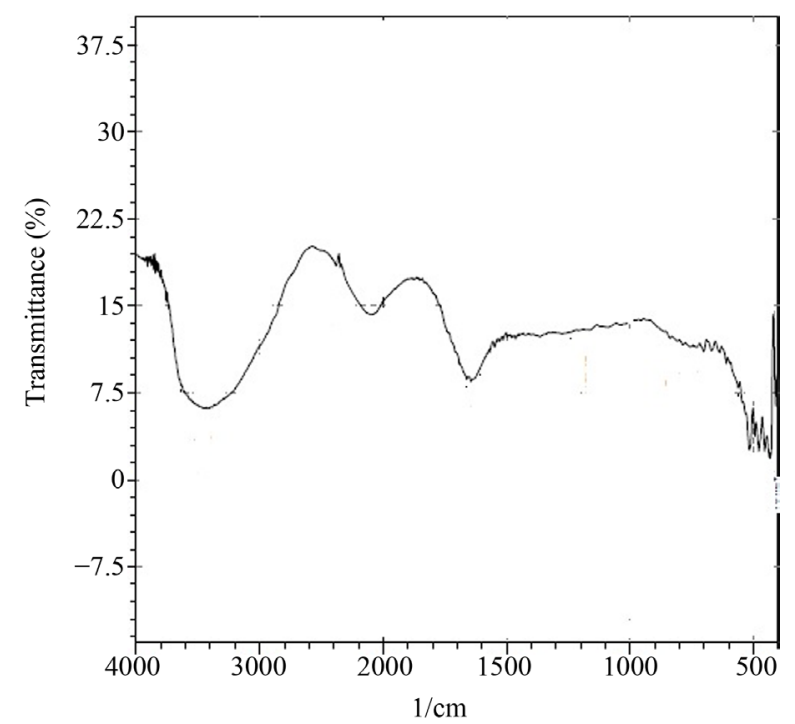

Figure 3. Typical infrared spectrum of polyurethane dispersion for $\mathrm{NCO} / \mathrm{OH}$ ratio of $\mathbf{1 . 4}$.

average particle size of PUD's was increased with the increase in the molar ratio of $\mathrm{NCO} / \mathrm{OH}$. This is due to the decreasing concentration of the carboxylic group with the increase in the molar ratio of $\mathrm{NCO} / \mathrm{OH}$.

As the particle size of the polymeric dispersion increases, the relative size of the water layer to the total particle size decreases. This in turn reduces the viscosity of the PUD's. As expected, the viscosity of PUD's showed a decreasing trend (Table 2) with the increasing molar ratio of $\mathrm{NCO} / \mathrm{OH}$.

\subsection{DSC Studies}

The effect of $\mathrm{NCO} / \mathrm{OH}$ molar ratio on the glass transition temperature was studied using DSC. The DSC curves of all the PUD's showed only single glass transition temperature $\left(T_{g}\right)$ and the values varied from 234 to $264 \mathrm{~K}$ (Table 2) with the increase of $\mathrm{NCO} / \mathrm{OH}$ molar ratio. As the $\mathrm{NCO} / \mathrm{OH}$ molar ratio increases, the concentration of hard segment (urea groups) and effective hydrogen bonding increases leading to the increase polymeric cross linking $[18,19]$. As the polymeric cross linking increases, the stability increases and thus showed the increase in $T_{g}$ with increase in $\mathrm{NCO} / \mathrm{OH}$ molar ratio.

\subsection{Stability of PUD}

The thermal stability of PUD's showed no precipitation for $24 \mathrm{~h}$ (Table 2). The freeze thaw stability of PUD 1 to PUD 5 was also presented in Table 2. As indicated in the table, precipitation was not observed during the freeze thaw stability test. However, when tested for storage stability (as indicated in Table 2), the stability decreases with increase in $\mathrm{NCO} / \mathrm{OH}$ molar ratio. This is due to the increase in average particle size of the PUD with NCO/ 
$\mathrm{OH}$ molar ratio as mentioned earlier.

\subsection{Chemical Resistance}

The acid resistance, alkali resistance and resistance in salt water of various PUD's were shown in Table 3. No change was observed for PUD 2 to 5 during acid resistance test. However, colour change was observed for PUD 1 during hydrochloric acid resistance test. All the PUD's showed excellent resistance towards $\mathrm{NaOH}$ solution for $24 \mathrm{~h}$. When testing was carried out in $\mathrm{NaCl}$ solution, PUD 2 to 4 showed no significant change, where as PUD 1 showed change in colour of the coated film. PUD 5 showed opaque nature after $24 \mathrm{~h}$ as presented in Table 3.

The solvent resistance was tested using acetone, methyl benzene and methyl ethyl ketone. The results of the test are presented in Table 3. Solvent resistance of PUD 2 and PUD 3 are found to be better than PUD 1, 4 and 5. In PUD 1 the coating gets dissolved with the organic sol- vents, where as PUD 4 and PUD 5 even though the film is hard in nature, transparency of the coated film gets reduced and become haze (as indicated in Table 3).

The solvent resistance was tested using acetone, methyl benzene and methyl ethyl ketone. The results of the test are presented in Table 3. Solvent resistance of PUD 2 and PUD 3 are found to be better than PUD 1,4 and 5 . In PUD 1 the coating gets dissolved with the organic solvents (as indicated in Table 3). PUD 4 and PUD 5 film remains hard in nature, however transparency of the coated film gets reduced and become haze after certain rubs as indicated in Table 3.

\subsection{Mechanical Properties}

Pencil hardness of the coated film on the teak wood is increased with increase of $\mathrm{NCO} / \mathrm{OH}$ molar ratio, which shows good hardness of the film (Table 4).

Cross cut adhesion (as indicated in Table 4) on the

Table 2. Physical Properties of synthesised PUD’s.

\begin{tabular}{|c|c|c|c|c|c|}
\hline Properties & PUD 1 & PUD 2 & PUD 3 & PUD 4 & PUD 5 \\
\hline Appearance & Milky white & Milky white & Milky white & Milky white & Milky white \\
\hline $\mathrm{pH}$ & 8.6 & 8.4 & 8.7 & 8.6 & 8.5 \\
\hline Viscosity (CPS) @ 30 $\mathrm{C}$ & 190 & 164 & 124 & 107 & 99 \\
\hline Particle size, Nm & 72.1 & 64.8 & 62.3 & 58.4 & 57.4 \\
\hline Glass transition temperature- $\operatorname{Tg}\left({ }^{\circ} \mathrm{C}\right)$ & -39 & -27 & -21 & -15 & -9 \\
\hline Storage stability (hydrolytic stability) (months) & 12 & 12 & 12 & 9 & 6 \\
\hline Thermal stability (ASTM E2550-2010) (Precipitate observed)* & 0 & 0 & 0 & 0 & 0 \\
\hline Freeze-thaw stability (ASTM D2337-2010) (Precipitate observed)* & 0 & 0 & 0 & 0 & 0 \\
\hline
\end{tabular}

" “0” stands for no precipitation.

Table 3. Chemical resistance of synthesised PUD’s.

\begin{tabular}{cccccc}
\hline Chemicals & PUD 1 & PUD 2 & PUD 3 & PUD 4 & PUD 5 \\
\hline Film appearance with 3\% HCl soln. & 1 & 0 & 0 & 0 & 0 \\
Film appearance with3\% NaOH soln. & 0 & 0 & 0 & 0 & 0 \\
Film appearance with 3\% NaCl soln. & 1 & 0 & 0 & 0 & 21 \\
Acetone (ASTM 5402-2006) (stable up to no. of rubs) & 20 & 23 & 24 & 19 & 21 \\
Methyl benzene (ASTM 5402-2006) (stable up to no. of rubs) & 18 & 23 & 23 & 18 & 18 \\
Methyl ethyl ketone (ASTM 5402-2006) (stable up to no. of rubs) & 15 & 21 & 21 & & 18 \\
\hline
\end{tabular}

0 : No change; 1 : Colour change; 2 : Opaque.

Table 4. Mechanical resistance of synthesised PUD's.

\begin{tabular}{|c|c|c|c|c|c|}
\hline Properties & PUD 1 & PUD 2 & PUD 3 & PUD 4 & PUD 5 \\
\hline Pencil hardness (ASTM D5402-2005) & HB & HB & $\mathrm{H}$ & $\mathrm{H}$ & $2 \mathrm{H}$ \\
\hline Cross cut adhesion (ASTM D3359-2009) & $4 \mathrm{~B}$ & $5 B$ & $5 B$ & $5 B$ & 3B \\
\hline Conical mandral (ASTM D522-2008) (Flexibility) & 1 & 1 & 1 & 2 & 2 \\
\hline Abrarasion resistance by Taber abraser (ASTM D4060-2010) weight loss after 1000 rotation in gms & 48 & 30 & 28 & 25 & 19 \\
\hline
\end{tabular}

\#1: flexible film; 2: breaking film. 
coated panel were investigated for its adhesion on the wood. For PUD 1, it was observed that about 5\% area was removed on the $1 \mathrm{~mm}$ cross cut adhesion test and thus classified as 4B. No coated film was removed for PUD 2, PUD 3, PUD 4 and it showed good adhesion on the coated wood, and classified as 5B. Nearly $10 \%$ of the coated film was removed for PUD 5 and film was brittle during the inspection and it was classified as $3 \mathrm{~B}$.

PUD's were applied on the metal panel and were tested for flexibility, PUD 1 to 3 film showed no break or crack, where as the film cracked for PUD 4 and PUD 5. Thus PUD 4 and 5 showed poor in flexibility (Table 4).

Taber abrasion test were resulted (Table 4) in reduction of the weight loss with increase in the $\mathrm{NCO} / \mathrm{OH}$ molar ratio and confirmed the increase in the hardness.

\section{Conclusion}

Aqueous anionic polyurethane dispersions were synthesized by increasing $\mathrm{NCO} / \mathrm{OH}$ molar ratio and the experimental results showed that the increase in $\mathrm{NCO} / \mathrm{OH}$ molar ratio increases the hardness of the polymer, on the contrary the film gets brittle, and hence its performance in the flexibility and adhesion is not satisfactory. The increase in hardness was due to the carbonate inter-chain interactions by hydrogen bonds with urethane and urea moieties. The stability and the chemical resistance were reduced in the higher molar ratio. Regarding wood coat applications, the PUD formed using caprolactone and TMXDI with the NCO/OH molar ratio of 1.4 or 1.6 is recommended for the application (both open pore and close pore application) in wood coat industry. This study needs to be further extended by studying the high temperature properties using thermo-gravimetric, supported by morphological studies.

\section{REFERENCES}

[1] O. Bayer, "Das Di-Isocyanat-Polyadditionsverfahren (Polyurethane)," Angewandte Chemie, Vol. 59, No. 9, 1947, pp. 257-272. http://dx.doi.org/10.1002/ange.19470590901

[2] C. H. Apburn, "Polyurethane Elastomers," 2nd Edition, Elsevier, Oxford, 1991.

[3] K. L. Noble, "Waterborne polyurethanes," Progress in Organic Coatings, Vol. 32, No. 1-4, 1997, pp. 131-136. http://dx.doi.org/10.1016/S0300-9440(97)00071-4

[4] M. Melchirs and M. Sonntag, "Recent Developments in Aqueous Two-Component Polyurethane (2K-PUR) Coatings," Progress in Organic Coatings, Vol. 40, No. 1-4, 2000, pp. 99-109. http://dx.doi.org/10.1016/S0300-9440(00)00123-5

[5] S. Y. Lee, J. S. Lee and B. K. Kim, "Preparation and Properties of Water-Borne Polyurethanes,” Polymer International, Vol. 42, No. 1, 1997, pp. 67-76. http://dx.doi.org/10.1002/(SICI)1097-0126(199701)42:1< 67::AID-PI660>3.0.CO;2-A
[6] M. M. Rahman and H. D. Kim, "Synthesis and Characterization of Waterborne Polyurethane Adhesives Containing Different Amount of Ionic Groups (I)," Journal of Applied Polymer Science, Vol. 102, No. 6, 2006, pp. 56845691. http://dx.doi.org/10.1002/app.25052

[7] Y. S. Kwak, E. Kim, B. H. Yoo and H. D. Kim, "Preparation and Properties of Waterborne Poly(urethane urea)s for Adhesives: The Effects of the 2,2-Bis(Hydroxylmethyl)Propionic Acid Content on the Properties," Journal of Applied Polymer Science, Vol. 94, No. 4, 2004, pp. 1743-1751. http://dx.doi.org/10.1002/app.21099

[8] T. Jeevananda, M. Begum and Siddaramaiah, "Studies on Polyaniline Filled PU/PMA Interpenetrating Polymer Networks,” European Polymer Journal, Vol. 37, No. 6, 2001, pp. 1213-1218. http://dx.doi.org/10.1016/S0014-3057(00)00228-7

[9] J. E. Yang, J. S. Kong, S. W. Park, D. J. Lee and H. D. Kim, "Preparation and Properties of Waterborne Polyurethane-Urea Anionomers. I. The Influence of the Degree of Neutralization and Counterion,” Journal of Applied Polymer Science, Vol. 86, No. 9, 2002, pp. 2375-2383. http://dx.doi.org/10.1002/app.11249

[10] D. C. Lee, R. A. Register, C. Z. Yang, S. L. Copper, "MDIBased Polyurethane Ionomers. 2. Structure-Property Relationships,” Macromolecules, Vol. 21, No. 4, 1988, pp. 1005-1008. http://dx.doi.org/10.1021/ma00182a027

[11] E. H. Klingenberg and S. N. Fazel, “Aqueous Polyurethane Dispersion and Method for Making and Using Same,” US Patent 20050107564 A1, 2005.

[12] C. Hepnurn, "Polyurethane Elastomer," 2nd Edition, Elsevier, New York, 1992. http://dx.doi.org/10.1007/978-94-011-2924-4

[13] W. Kemp, “Organic Spectroscopy,” 3rd Edition, Macmillan Press Ltd., 1991, pp. 60-71.

[14] Y. R. Sharma, "Elementary Organic Spectroscopy,” S. Chand \& Company Ltd., Newdelhi, 2007, p. 101.

[15] S. Ahmad, S. M. Ashraf, E. Sharmin, F. Zafer and A. Hasnat, "Progress in Crystal Growth and Characterization of Materials,” 2002, pp. 83-88.

[16] S. Subramani, Y. J. Park, I. W. Cheong and J. H. Kim, "Polyurethane Ionomer Dispersions from a Blocked Aromatic-Diisocyanate Prepolymer,” Polymer International, Vol. 53, No. 8, 2004, pp. 1145-1152.

[17] B. K. Kim and J. C. Lee, "Modification of Waterborne Polyurethanes by Acrylate Incorporations,” Journal of Applied Polymer Science, Vol. 58, No. 7, 1994, pp. 1117-1124. http://dx.doi.org/10.1002/app.1995.070580705

[18] T. W. Pechar, G. L. Wilkes, B. Zhou and N. Luo, "Characterization of Soy-Based Polyurethane Networks Prepared with Different Diisocyanates and Their Blends with Petroleum-Based Polyols,” Journal of Applied Polymer Science, Vol. 106, No. 4, 2007, pp. 2350-2362. http://dx.doi.org/10.1002/app.26569

[19] G. Ligadas, J. C. Ronda, M. Galia and V. Cadiz, "Poly (ether urethane) Networks from Renewable Resources as Candidate Biomaterials: Synthesis and Characterization," Biomacromolecules, Vol. 8, No. 2, 2007, pp. 686-692. http://dx.doi.org/10.1021/bm060977h 